\title{
The Soils Within the Perimeter of the Archaeological \\ Site no. 1, Caracal-Ring Road (Agricultural Research-Development Station) and the Possible Influence of Roman Dwelling on Them
}

\author{
Anca-Luiza Stănilă (Corresponding author) \\ Department research in soil science, agrochemical and environmental protection \\ Laboratory of soil sciences and sustainable development \\ National Research Institute for Soil Science \\ Agrochemistry and Environment Protection - ICPA \\ 61 Mărăşti Blvd, District 1, 011464, Bucharest, Romania \\ E-mail: luizastanila2011@yahoo.com
}

\begin{abstract}
Nicolae Cruceru
Institute of Speleology „Emil Racovita”, Bucharest, Romanian Academy,

13 September Street, No. 13, District 5, 050711, Bucharest, Romania
\end{abstract}

\section{Mircea Negru}

Spiru Haret University, Department of Law, Political and Administrative Sciences, Berceni Street, No.24, District 4, 041917, Bucharest, Romania

Received: Oct. 9, 2020

doi:10.5296/jas.v9i1.17916
Accepted: Oct. 30, $2020 \quad$ Published: Nov. 5, 2020

URL: https://doi.org/10.5296/jas.v9i1.17916

\section{Abstract}

Soils represent that superficial deposit from the land surface in a continuous evolution, but with a high vulnerability to climate change and anthropogenic interventions. The current soil 
was born in a long period of time (numbering hundreds of years) through pedogenetic factors and processes, but also anthropogenic influences on the parent material.

The purpose of this article is to investigate the soil on the territory of a Roma village (vicus), located on both sides of the Caracal Municipality Ring Road. This is located near the Roman road from Romula (Resca village, Dobrosloveni commune, Olt County), the residence of the Dacia Inferior (Malvensis) Roman province's governor and Sucidava (Corabia-Celei, Olt County), in a region where there was a fertile land favourable to agriculture.

The parental materials (carbonate loess-like deposits loamy-clayey loam) belonging to that period are well represented in the soil horizons starting $25-30 \mathrm{~cm}$ from the surface to a variable depth, a fact which will be validated by on-going geophysical studies. The dominant soil is argic chernozem, belonging to the cernisols class specific to the plain area, but with a higher amount of clay. It is important to note that in the 4 soil profiles analysed in detail we find differences in soil texture within the horizons, even if there are traces of the Roman period.

Keywords: argic chernozem, roman vestiges, soil texture, Caracal Plain, compaction

\section{Introduction}

The current study represents the beginning of interdisciplinary research in the Roman region near the lower Olt valley, within the Caracal Plain and on Olt's terraces. In this material, we try to synthesize certain morphological characteristics of the soil from a space inhabited by many civilizations, including the Roman one.

The soil began to be scientifically researched once the foundations of the discipline were laid in the latter part of the 19th century (Brevik \& Hartemink, 2010). The history of soil science appears well structured and argued in the late 1980s, in true treatises on the "history of soil science" (Boulaine, 1989; Krupenikov, 1992; Yaalon \& Berkowicz, 1997; Warkentin, 2006). It is interesting that soil and man have had intense interactions since 10-11 millennia ago in the areas of Egypt, Greece, Rome and beyond (Hartemink, 2008; Hartemink \& McBratney, 2008). The period we are interested in is well summarized by Krupenikov, 1992. It covers the 11.000 BP - 1.900 AD section, a period in which people took into account the characteristics and properties of the soil and also its suitability for certain crops (Brevik \& Hartemink, 2010), but also the diversified use of working methods and even interventions that have created irrigation systems dating back to 9.500 BP in southern Iraq today (Troen et al., 2004).

From the point of view of agriculture, the Roman Empire relied on the Greek system with a support for the improvement and fertilization of the soil, including based on manure (Krupenikov, 1992; Winiwarter, 2006).

The important contribution of the empire is represented by the protection and the desire to reduce soil degradation, especially through terracing (Troen et al., 2004). Therefore, the period of maximum expansion of the Roman Empire was favourable for the rational use of soil and its maintenance in optimal parameters. Today, the state of the soil can sometimes be a characteristic, a status quo of the development of a country's society (Pozniak \& Havrysh, 2020). 


\section{Macrothink}

Journal of Agricultural Studies

ISSN 2166-0379

2021, Vol. 9, No. 1

Plains, interfluvial fields and even terraces hide many settlements from prehistory to the medieval period. In the eastern sector of the Caracal Plain, east of the town with the same name, there are traces of a Roman site, with well-represented roads and houses, and as we approach the village of Resca, the former Romula settlement, one of the most important centres of the empire, the traces of the empire become more and more evident. In the experimental field are traces of the settlement "fossilized" by the upper horizons of the soil represented by the road pavement, house bricks, as well as ceramic objects (Figure 1,2).

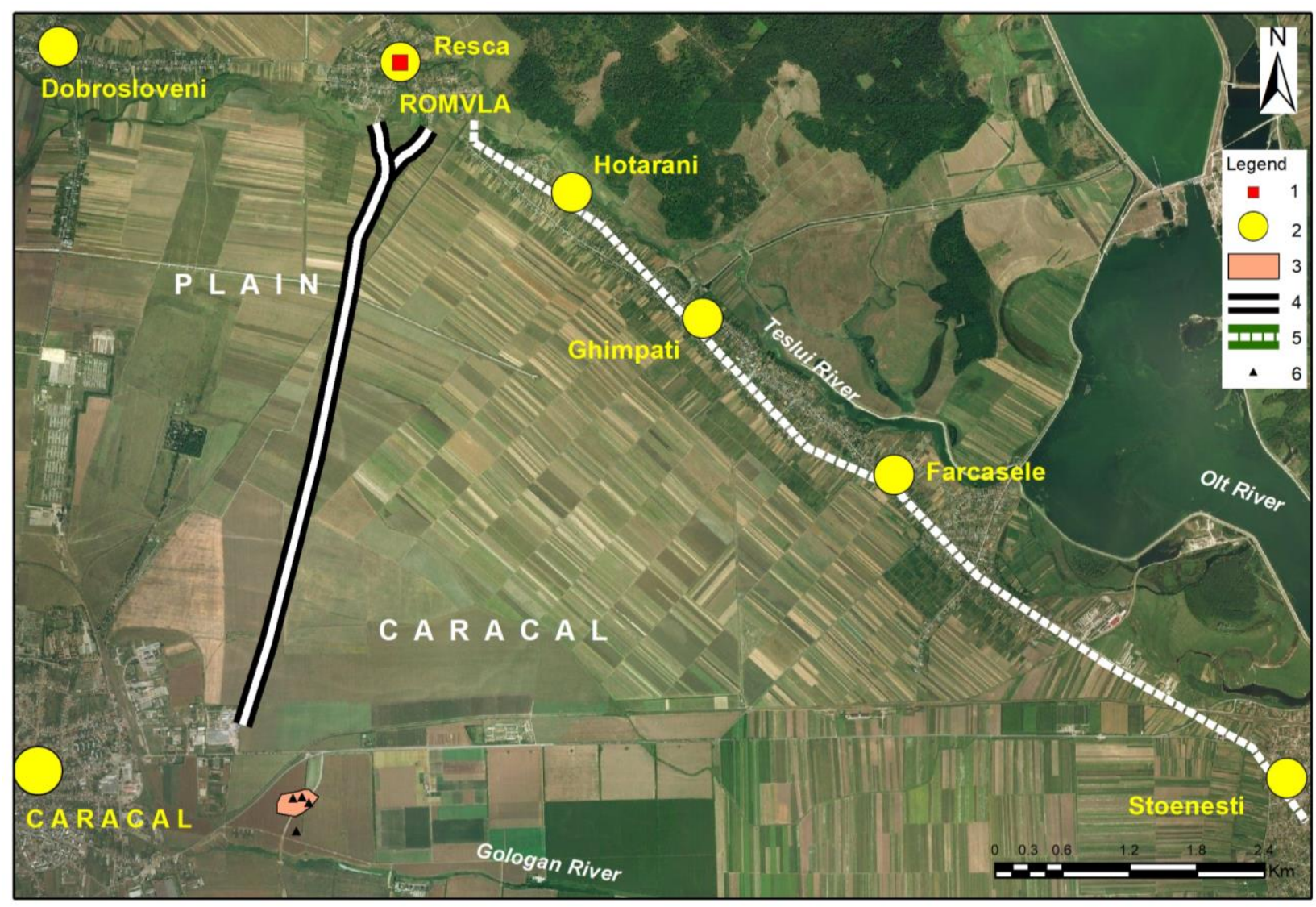

Figure 1 . The location of the study area: 1 - roman locality; 2 - current location; 3 - roman settlement in the study area; 4 - roman road; 5 - presumed roman road; 6 - pedological profiles

Archaeological diagnostic researches initiated in 2012 have highlighted vestiges belonging to a village (vicus) from the Roman era, located in the area of Caracal Municipality Ring Road, east of the Gologan brook (Negru et al., 2013).

In order to elucidate the situation, in 2019, new archaeological field assessments were undertaken in the area of this site. Following the identification of some areas with Roman archaeological materials (bricks, tiles, ceramic fragments), magnetometric investigations were carried out by Professor Mihai Furnica, which have indicated the presence of archaeological structures (buildings). 


\section{MInstitute Macrothink}
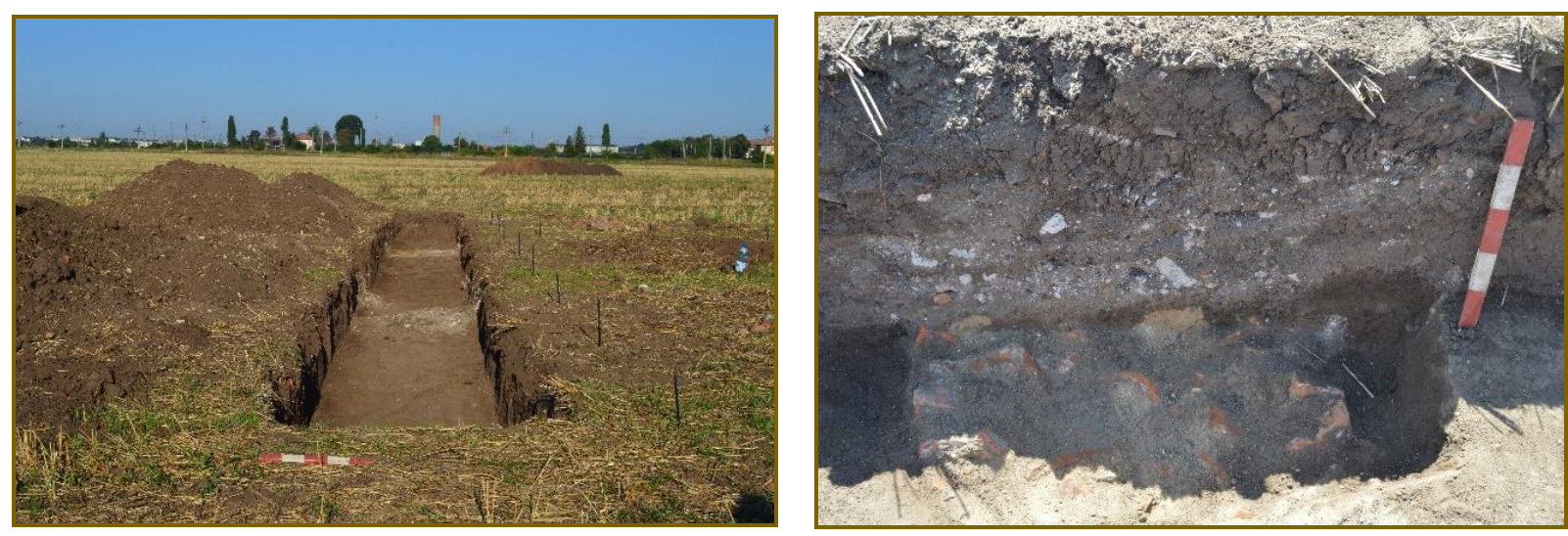

Figure 2. Caracal-Ring Road. Roman edifice No 1. General and detailed picture of the foundation

Between August 18th and September 5th, 2020, with the authorization of the Ministry of Culture no. 307/24.07.2020, new diagnostic researches were undertaken in order to delimit this archaeological site. A total of 8 archaeological sections were practiced, in which two archaeological levels from the Roman era and several archaeological structures (a building and two pits with materials from the Roman era) were captured. Within some of these sections, pedological profiles were also practiced in order to investigate the impact of anthropogenic activities from the Roman era on the soil.

The important fact is that the current agricultural works (we assume that from the last 50 years) were carried out without affecting much the historical vestiges.

\section{Study site:}

The area under study is located near the contact between Leu-Rotunda Plain and the Plain/Field of Caracal located east of the homonymous locality, delimited somewhat by Gologan brook (or Caracal brook, as the locals also call it) in the south and the Caracal-Alexandria railway in north (Figure 3).

The Caracal Plain ${ }^{1}$ is part of the Oltenia Plain and also belongs to the west of the Romanian Plain or the lower Danube Plain. Here there are three series of surfaces: plains, terraces and meadows (Valsan, 1971), of which the first dominates as a surface and presents itself as an extension of the high Getic Piedmont in which the levels of terraces were carved (Cotet, 1957, 1976). From a morphogenetic point of view, it is a plain of terraces arranged along the large rivers and the main tributaries (Posea, 2005; Cruceru, 2008). The field is also located on a terrace (the 3rd) that actually occupies the entire Caracal Plain (Romanian Geography, Vol. V, 2005). This space under study is located at an altitude of $92-95 \mathrm{~m}$, is dominated by the predominance of gentle/flat shapes, but where we also distinguish a series of cenote-like compaction and suffusion micro-depressions, but also traces of former watercourses.

1 Sometimes also met under the name of Romanați Plain (Cotet, 1973). 


\section{Macrothink}

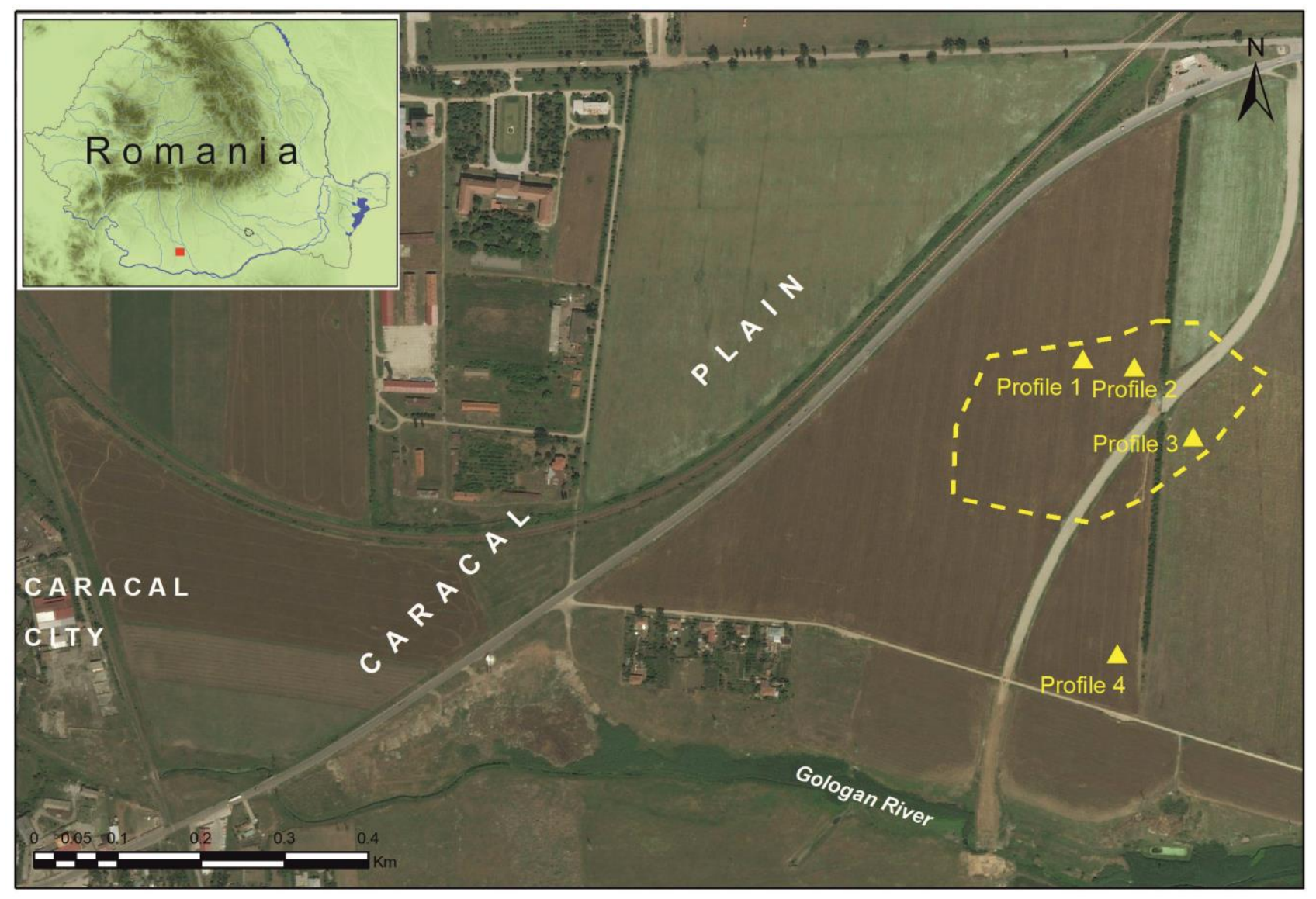

Figure 3. Location of study area: roman locality site with broken line and location of the pedological profiles

Geologically, we are located on the crystalline foundation of the Wallachian Platform dominated by mesometamorphic, epimetamorphic and magmatite crystalline schists over which we have important sedimentary deposits (Mutihac, Ionesi, 1974). Near the surface, younger deposits (Quaternary) are present, dominant being the deluvio-proluvial ones (sands and gravels) and less often the loess.

Ground waters are present at a depth of $10-15 \mathrm{~m}$ as well, sometimes even more and with a deferred/ slow drainage (Cotet, 1976). From a climatic point of view, we are in a temperate climate with arid influences with an average duration of sunshine that exceeds the value of 2000 hours per year, with an average annual temperature of $10-11^{\circ} \mathrm{C}$ and a quantity of precipitation of about $550 \mathrm{~mm} / \mathrm{year}$. Hydrographically, we are located in the Olt basin, which gathers all the rivers from the west of the Caracal Plain, to which is added the Caracal or Gologan brook that drains the south of the study area. The natural vegetation has been replaced centuries ago for the expansion of agricultural land, but we are in the steppe area (Stănilă, 2006).

\section{Materials and Methods}

The basic elementary unit in the research and mapping of the soil cover was the soil profile (the pedon), which allowed the study of the morphological properties of the soils and some of 
their agro-productive assessments. As a result, soils were classified based on their intrinsic properties, respectively the properties of the soil profile, taking into account horizons and diagnostic characters (Stănilă \& Parichi, 2001). The soil profiles were placed on the field so as to form a network of studied points. As methods, the method of parallel sleepers was used, with itineraries located almost at equal distances, with a less varied soil cover. The soil boundaries highlight this situation by interpreting two sleepers and based on the micro and mezorelief observations in the field.

The soil profiles were made using mechanical equipment and manual finishes up to a maximum depth of $240 \mathrm{~cm}$. The soil profiles were analysed in the field, and later, with the samples taken, the study was finalized in the laboratory. The samples were taken in special micromonolite like boxes and in plastic bags with vacuum closure for their transportation to the laboratory. In the field, the following tools were used: for planimetry and topography differential DGP, Garmin CSx 60 GPS, Totrec Bc21 (thermohygrometer for air temperature and humidity), Tecpel pH707 (pH meter and soil moisture meter), Foretry 550 (Rangefinder laser - for distances and angles); measuring tape (3 $\mathrm{m}$ and $25 \mathrm{~m})$.

In order to establish the diagnosis of the soils, their morphological features were taken into account, namely the thickness of the horizons, their colour while wet and dry, the texture, the structure, compactness, adhesiveness, plasticity, the neoformations according to the "Methodology development of soil studies" ICPA Bucharest, 1987.

\section{Results and Discussions}

Present climate changes represent a moment in the history of Earth and implicitly of soils. At the same time, there is a significant increase in the areas removed from the agricultural circuit by means of the new socio-economic infrastructure, not taking into account the destruction of the areas with fertile soils, which will subsequently require an expensive ecological reconstruction.

The dominant soils in the study area are argic chernozems, belonging to the cernisols class (Ispas \& Stănilă, 2015).

Characteristic for argic chernozems is the obvious accumulation of organic matter (relatively base saturated) in the upper part of the soil profile, having as diagnostic horizon an type A molic (Am) horizon continued with an intermediate horizon (AB) having molic horizon colours, at least in the superior part (on minimum 10-15 cm) and at least on the sides of the structural aggregates (SRTS, 2012) (Florea et al., 2012).

In optimal humidity (especially at the beginning of the growing season) and well-represented grassy vegetation conditions, the bioaccumulation process is much more intense forming calcium humus, intimately mixed with the mineral part, which gives the soil a very dark colour.

Regarding the alteration and leaching, during the soil formation, a slightly higher amount of clay is formed at the level of the argic Bt horizon. Argic chernozems have a differentiated texture on the profile due to clay migration, i.e. in the argic Bt horizon they have a higher clay content than in the Am surface horizon. The structure in Am is grainy-polyhedral 


\section{Macrothink}

Journal of Agricultural Studies ISSN 2166-0379 2021, Vol. 9, No. 1

subangular, well developed, but at the level of the argic Bt horizon it is well highlighted prismatic-columnoid.

In the profile in which there are no traces of Roman settlement, the soil compactness is lower, and the $\mathrm{pH}$ has a value of 6.9 (neutral), in the other 3 profiles, the $\mathrm{pH}$ reaction is slightly acidic with values between 6-6.4. At the same time, the soil moisture is lower in the soil unaffected by the Roman impact, due to the faster circulation of water through the soil horizons. Recent agricultural crops - vines and later wheat - are not affected by the presence of Roman elements in the upper third of the soil profile.

We took into account the area with Roman influence located on the argic chernozem type soil using data from 4 pedological profiles, of which 3 bear the historical impact of the empire and one outside the technical-municipal use, used only for agricultural purposes. Below we present the description of the 4 soil profiles' morphological characters (Figure 4):

The morphological characteristic of the argic chernozem soil. Profile 1 - Caracal Plain, threshed wheat crop, $44^{\circ} 6^{\prime} 49.21^{\prime \prime} \mathrm{N} ; 2^{\circ}{ }^{\circ} 3^{\prime} 0.98$ 'E (Figure 4a)

Amp: 0-10 cm; medium loam, very dark brown (10YR 2/2) when wet, very dark grey brown (10YR 3/2) when dry, grainy small-medium-polyhedral subangular, crumbly when wet, humid, moderately loose, moderately plastic, moderately adhesive, fine, rare cracks, coprolites, frequent thin grassy roots, gradual transition;

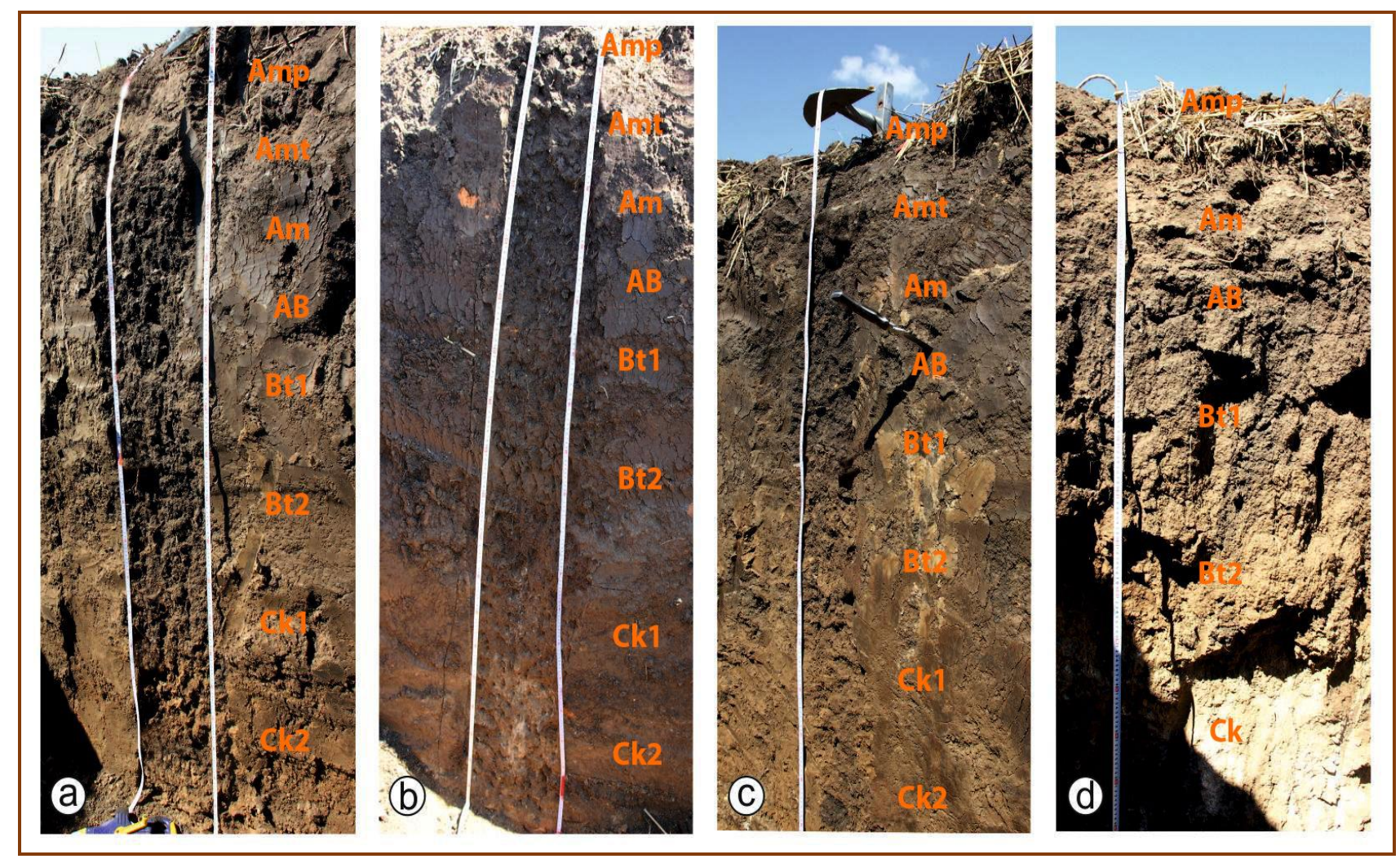

Figure 4. Argic chernozem within the archaeological site no. 1 - Caracal Plain: a. Profile 1; $b$. Profile 2; c. Profile 3; d. Profile 4 
Amt: 11-30 cm; medium loam, same colour, unstructured, crumbly when wet, moderately plastic and adhesive, humid-moist, moderately compacted, fine, rare cracks, coprolites, traces of Roman elements (bricks, ceramics), frequent thin grassy roots, clear transition;

Am: 31-76 cm; medium loam, very dark brown (10YR 2/2) when wet, very dark grey (10YR 3/1) when dry, grainy medium-polyhedral subangular, crumbly when wet, humid, moderately plastic, moderately adhesive, slightly compact, fine and very rare cracks, coprolites, traces of Roman elements (bricks, ceramics), thin grassy roots, gradual transition;

AB: 77-95 cm; clay loam, very dark brown (10YR 2/2) when wet, dark brown (10YR 3/3) when dry, medium-large angular polyhedron, moist, moderately plastic and adhesive, slightly compact, clay films on the sides of the structural aggregates, very fine and very rare cracks, coprolites, rare thin grassy roots, gradual transition;

Bt $_{1}$ : 96-132 cm; clay loam, very dark grey-brown (10YR 3/2) with spots of dark brown-brown (10YR 4/4) when wet, brown (10YR 4/3) when dry, prismatic, moist-dry, firm when wet, moderately plastic, moderately adhesive, compact, clay films on the sides of the structural aggregates, very fine and very rare cracks, rare thin grassy roots, gradual transition;

Bt2: 133-149 cm; clay loam, dark yellowish brown (10YR 3/4) when wet, dark yellowish brown (10YR 3/6) when dry, prismatic-columnoid, moist-dry, crumbly when wet, slightly plastic, moderately adhesive, slightly compact, clay films on the sides of the structural aggregates, very fine and very rare cracks, rare thin grassy roots, gradual transition;

Ck1: 150-177 cm; medium loam, dark yellowish brown (10YR 4/4) when wet, dark yellowish brown (10YR 4/6) when dry, unstructured, moist, crumbly when wet, slightly plastic and adhesive, slightly compact, mass effervescence, $\mathrm{CaCO}_{3}$ stains and veins, very fine and very rare cracks, gradual transition;

Ck$_{2}$ : 178-204 cm; medium loam, dark yellowish brown (10YR 4/6) when wet, yellowish brown (10YR 5/6) when dry, unstructured, moist-dry, crumbly when wet, slightly plastic and adhesive, slightly compact, strong mass effervescence, $\mathrm{CaCO}_{3}$ pseudomycelia and veins.

The morphological characteristic of the argic chernozem soil. Profile 2 - Caracal Plain, threshed wheat crop, $44^{\circ} 6^{\prime} 50.01 " N$; $24^{\circ} 23 ' 3.26$ ' $E$ (Figure 4b).

Amp: 0-10 cm; medium loam, black (10YR 2/1) when wet, very dark brown (10YR 2/2) when dry, small to medium-grained, crumbly when wet, humid, moderately loose, moderately plastic, moderately adhesive, fine, rare cracks, coprolites, frequent thin grassy roots, gradual transition;

Amt: 11-29 cm; medium loam, very dark brown (10YR 2/2) when wet, very dark grey (10YR 3/1) when dry, unstructured, crumbly when wet, moderately plastic and adhesive, humid-moist, moderately compacted, fine, rare cracks, coprolites, frequent thin grassy roots, clear transition;

Am: 30-56 cm; medium loam, very dark brown (10YR 2/2) when wet, very dark grey brown (10YR 3/2) when dry, grainy small-medium-polyhedral subangular, crumbly when wet, moist, 
moderately plastic and adhesive, compact, fine and very rare cracks, coprolites, traces of Roman elements (bricks, ceramics), frequent thin grassy roots, gradual transition;

AB: 57-82 cm; clay loam, very dark grey-brown (10YR 3/2) when wet, dark yellowish brown (10YR 3/4) when dry, medium-high angular polyhedral, crumbly when wet, moist, moderately plastic and adhesive, compact, clay films on the sides of the structural aggregates, fine and very rare cracks, coprolites, rare thin grassy roots, gradual transition;

Bt $_{1}$ : 83-102 cm; clay loam, dark yellowish brown (10YR 3/6) when wet, dark yellowish brown (10YR 4/4) when dry, prismatic, crumbly when wet, dry, moderately plastic and adhesive, moderately compact, clay films on the sides of the structural aggregates, very fine and very rare cracks, pseudomycelias, $\mathrm{CaCO}_{3}$ vines and stains, rare thin grassy roots, gradual transition;

Bt $_{2}$ : 103-141 cm; clay loam, dark yellowish brown (10YR 4/4) when wet, brown (10YR 5/3) when dry, columnoid-prismatic, crumbly when wet, dry, moderately plastic and adhesive, slightly compact, clay films on the sides of the structural aggregates, very fine and very rare cracks, $\mathrm{CaCO}_{3}$ pseudomycelias and loess dolls, rare thin grassy roots, gradual;

Ck1: 141-190 cm; loam, dark yellowish brown (10YR 4/6) when wet, yellowish brown (10YR 5/4) when dry, unstructured, crumbly when wet, dry, slightly plastic and adhesive, slightly compact, strong mass effervescence, $\mathrm{CaCO}_{3}$ pseudomycelias, veins and stains, gradual transition;

Ck2: 191-220 cm; loam, yellowish brown (10YR 5/4) when wet, yellowish brown (10YR 5/8) when dry, unstructured, crumbly when wet, dry, slightly plastic and adhesive, slightly compact, strong mass effervescence, $\mathrm{CaCO}_{3}$ pseudomycelias and stains.

The morphological characteristic of the argic chernozem soil. Profile 3 - Caracal Plain, threshed wheat crop, $44^{\circ} 6^{\prime} 47.49^{\prime \prime} \mathrm{N} ; 2^{\circ} 23^{\prime} 5.29^{\prime \prime} \mathrm{E}$ (Figure 4c)

Amp: 0-12 cm; medium loam, black (10YR 2/1) when wet, very dark brown (10YR 2/2) when dry, small-medium grainy, crumbly when wet, moist, moderately loose, moderately plastic, moderately adhesive, fine, rare cracks, coprolites, frequent thin grassy roots, gradual transition;

Amt: 13-31 cm; medium loam, same colour, unstructured, crumbly when wet, moderately plastic and adhesive, humid, moderately compacted, fine, rare cracks, coprolites, traces of Roman elements (bricks, ceramics), frequent thin grassy roots, clear transition;

Am: 32-47 cm; medium loam, very dark brown (10YR 2/2) when wet, very dark grey (10YR 3/1) when dry, small-medium-polyhedral subangular grainy, crumbly when wet, moist, moderately plastic and adhesive, compact, fine and very rare cracks, coprolites, traces of Roman elements (bricks, ceramics), frequent thin grassy roots, gradual transition;

AB: 48-79 cm; clay loam, very dark brown (10YR 2/2) when wet, very dark grey brown (10YR 3/2) when dry, medium-high angular polyhedral, crumbly when wet, moist-dry, moderately plastic and adhesive, compact, clay films on the sides of the structural aggregates, 
fine and very rare cracks, coprolites, rare thin grassy roots, gradual transition;

Bt $_{1}$ : 80-102 cm; clay loam, brown (10YR 4/3) when wet, dark yellowish brown (10YR 4/6) when dry, prismatic, crumbly when wet, dry, moderately plastic and adhesive, moderately compact, clay films on the sides of the structural aggregates, very fine and very rare cracks, rare thin grassy roots, gradual transition;

Bt $_{2}$ : 103-164 cm; clay loam, dark yellowish brown (10YR 4/6) when wet, yellowish brown (10YR 5/4) when dry, columnoid-prismatic, crumbly when wet, dry, moderately plastic and adhesive, slightly compact, clay films on the sides of the structural aggregates, very fine and very rare cracks, $\mathrm{CaCO}_{3}$ veins and stains, rare thin grassy roots, gradual transition;

Ck1: 165-216 cm; loam, grey-brown (10YR 5/2) when wet, yellowish-brown (10YR 5/6) when dry, unstructured, crumbly when wet, dry, slightly plastic and adhesive, slightly compact, strong mass effervescence, pseudomycelia, $\mathrm{CaCO}_{3}$ veins and stains, gradual transition;

Ck2: 217-260 cm; loam, yellowish brown (10YR 5/6) when wet, yellowish brown (10YR 5/8) when dry, unstructured, crumbly when wet, dry, slightly plastic and adhesive, slightly compact, strong mass effervescence, pseudomycelia and $\mathrm{CaCO}_{3}$ stains.

The morphological characteristic of the argic chernozem soil. Profile 4 - Caracal Plain, threshed wheat crop, $4^{\circ}$ 6'37.98' $^{\prime} \mathrm{N} ; 2^{\circ} 23^{\prime} 2.24^{\prime \prime} \mathrm{E}$ (Figure 4d)

Amp: 0-25 cm; medium loam, black (10YR 2/1) when wet, very dark brown (10YR 2/2) when dry, crumbly when wet, unstructured (structure destroyed by agricultural machinery), moist, moderately plastic, moderately adhesive, moderately loose, rare fine cracks, coprolites, frequent thin grassy roots, gradual transition;

Am: 26-48 cm; medium loam, same colour, small-medium-polyhedral angular grainy, crumbly when wet, moist-dry, moderately plastic and adhesive, slightly compact, rare fine cracks, coprolites, frequent thin grassy roots, gradual transition;

AB: 49-67 cm; clay loam, dark brown (10YR 3/2) when wet, dark grey (10YR 4/1) when dry, polyhedral angular-grainy small-medium, crumbly when wet, moist-dry, moderately plastic and adhesive, slightly compact, fine and very rare cracks, coprolites, clay films on the sides of the structural aggregates, rarer thin grassy roots, gradual transition;

Bt 1 : 68-103 cm; clay loam, dark brown (10YR 3/3) when wet, dark brown (10YR 4/3) when dry, medium-large prismatic, crumbly when wet, dry, moderately plastic and adhesive, moderately compact, fine and very rare cracks, coprolites, clay films on the sides of the structural aggregates, humus leakages on the sides of the structural aggregates, rare thin grassy roots, gradual transition;

Bt2: 104-140 cm; clay loam, dark brown (10YR 4/3) when wet, yellowish brown (10YR 5/4) when dry, medium-large prismatic-columnoid, crumbly when wet, dry, moderately plastic and adhesive, very fine and very rare cracks, slightly compact, clay films on the sides of the structural aggregates, humus leakages on the sides of the structural aggregates, rare thin 
grassy roots, pseudomycelias, $\mathrm{CaCO}_{3}$ vines and strains, mass effervescence, gradual transition;

Ck: 140-220 cm; loam, yellowish brown (10YR 5/4) when wet, light brown (10YR 6/3) when dry, unstructured, crumbly when wet, dry, moderately plastic and adhesive, slightly compact, very fine and very rare cracks, pseudomycelias, strains, $\mathrm{CaCO}_{3}$ veins, strong mass effervescence.

\section{Conclusions}

Between the 3 profiles in which we have traces of Roman civilization and the fourth where we do not have Roman material elements there are differences that influence the permeability of water in the soil, respectively the eluviation-illuviation processes, the $\mathrm{pH}$ reaction.

Compaction is one of the most common forms of physical degradation of the studied argic chernozems. The compaction process appears as an effect of the mechanical stress determined by the traffic of agricultural machines on the soil surface in inadequate conditions of workability and trafficability. By compaction, the macroporous space of the soil is reduced, having as direct effect the reduction of the apparent density and, indirectly, the loss of water absorption capacity. Compaction occurs in the initial phase in the soil surface horizon, but over time, subsoil layers are affected by this negative process, due to the depth of ploughing (Canarache, 1990).

The analysed argic chernozems fall into the category of soils with medium to good fertility, and can be suitable for all uses (field crops, vegetables, vineyards and fruit trees).

In order to create the optimal conditions for plant development, measures are required to regulate the redox processes in soils, by improving the structuring state, the water and air regime by using the appropriate agrotechnical methods. In dry periods, irrigation is required; organic and mineral fertilizers bring significant increases in production.

This study is part of a national program of multi and interdisciplinary research, which aims to investigate the real estate archaeological heritage, its spatial disposition and complex relationships between human settlements and the ancient environment, in the Roman city of Romula, Dacia Inferior province (Malvensis).

\section{Acknowledgements}

Thanks your city hall of Caracal Municipality, Mr Eng. Ion Marian Doldurea and Mr Dr. Sabin Popovici, Director of the Romanati Museum of Caracal for the support given in achieving of pedological profiles, that is to Mr. Marius Bran, Director of the Agricultural Research-Development Station, Caracal.

\section{References}

(1987). Methodology development of soil studies (3 Volume). ICPA, Bucharest, 726 p.

(2005). Geography of Romania V. The Romanian plain, the Danube, the Dobrogea Plateau, the Romanian Black Sea coast and the Platform Continental. Romanian Academy Publishing House, Bucharest, 968 p. 
Boulaine, J. (1989). Histoire des Pédologues et de la Science des Sols. INRA, Paris.

Brevik, E. C., \& Hartemink, A. E. (2010). Early soil knowledge and the birth and development of soil science, Catena, 83, Elsevier, p.23-33. https://doi.org/10.1016/j.catena.2010.06.011.

Canarache, A. (1990). Agricultural soils physical. Ceres Publishing House, Bucharest, 268 p.

Cotet, P. (1957). Oltenia Plain. Technical Publishing House, Bucharest.

Cotet, P. (1973). Geomorphology of Romania. Technical Publishing House, Bucharest, 414 p.

Cotet, P. (1976). Romanian Plain. Ceres Publishing House, Bucharest, 256 p.

Cruceru, N. (2008). Introduction to Romania's regional geography. Publishing of the Romania de Maine Foundation, Bucharest, 356 p.

Florea, N., Munteanu, I., Rusu, C., Dumitru, M., Ianoş, Gh., Răducu, Daniela, Rogobete, Gh. \& Țărău, D. (2012). Romanian System of Soil Taxonomy. Sitech Publishing House, Bucharest, $206 \mathrm{p}$.

Hartemink, A. E., \& McBratney, A. (2008). A soil science renaissance. Geoderma, 148, p. 123-129. https://doi.org/10.1016/j.geoderma.2008.10.006.

Hartemink, A., E. (2008). Soils are back on the global agenda. Soil Use \& Management, 24, p. 327-330. https://doi.org/10.1111/j.1475-2743.2008.00187.x.

Ispas, Şt. \& Stănilă, Anca-Luiza (2015). Soils Romania. Publisher Valahia University Press, Targoviste, 246 p.

Krupenikov, I. A. (1992). History of Soil Science From its Inception to the Present. Oxonian Press, New Delhi.

Mutihac, V., \& Ionesi, L. (1974). Geology of Romania. Technical Publishing House, Bucharest, $646 \mathrm{p}$.

Negru, M., Mihai, G. \& Popovici, S. (2013). Caracal, Olt County, point: The bypassing version of the Caracal Municipality, Ministry of Culture, The chronology of archaeological research in Romania. A-XLVII-a National Session of Archaeological Reports, Craiova, 27-30 May 2013, The Publishing House of Alexandru Ioan Cuza University, Iasi, p. 214-215.

Posea, Gr. \& Cruceru, N. (2005). Geomorphology Romania. Romania for Tomorrow Publishing House, Bucharest, 364 p.

Pozniac, S., \& Havrysh, N. (2020). Social soil science as a new approach in soil science. Polish Journal of Soil Science, Vol. LIII/1, PL ISSN 0079-2985. https://doi.org/10.17951/pjss.2020.53.1.73.

Stănilă, Anca-Luiza \& Parichi, M. (2001). Land mapping. Publishing of the Romania de Maine Foundation, Bucharest, 160 p.

Stănilă, Anca-Luiza (2006). Biogeography. Romania for Tomorrow Publishing House, 
Bucharest, 254 p.

Troeh, F. R., Hobbs, J. A., \& Donahue, R. L. (2004). Soil and Water Conservation for Productivity and Environmental Protection. 4th Ed. Prentice Hall, Upper Saddle River, NJ.

Valsan, G. (1971). Works chosen, The boundaries of the Romanian Plain. Publishing House, Scientific, Bucharest, 694 p.

Warkentin, B. P. (2006). Footprints in the Soil: People and Ideas in Soil History. Elsevier, Amsterdam.

Winiwarter, V. (2006). Soil scientists in Ancient Rome, In: Warkentin, B.P., Footprints in the Soil: People and Ideas in Soil History. Elsevier, Amsterdam, p. 3-16.

Yaalon, D. H., \& Berkowicz, S. (1997). History of Soil Science - International Perspectives. Catena Verlag, Reiskirchen, 438 p.

\section{Copyright Disclaimer}

Copyright for this article is retained by the author(s), with first publication rights granted to the journal.

This is an open-access article distributed under the terms and conditions of the Creative Commons Attribution license (http://creativecommons.org/licenses/by/4.0/). 